\title{
Epithelial-to-mesenchymal transition in cancer: complexity and opportunities
}

\author{
Yun Zhang $(\bowtie)^{1}$, Robert A. Weinberg $(\bowtie)^{1,2,3}$ \\ ${ }^{1}$ Whitehead Institute for Biomedical Research; ${ }^{2}$ MIT Department of Biology; ${ }^{3}$ Ludwig/MIT Center for Molecular Oncology, Cambridge, MA \\ 02142, USA \\ (C) The Author(s) 2018. This article is published with open access at link.springer.com and journal.hep.com.cn 2018
}

\begin{abstract}
The cell-biological program termed the epithelial-to-mesenchymal transition (EMT) plays an important role in both development and cancer progression. Depending on the contextual signals and intracellular gene circuits of a particular cell, this program can drive fully epithelial cells to enter into a series of phenotypic states arrayed along the epithelial-mesenchymal phenotypic axis. These cell states display distinctive cellular characteristics, including stemness, invasiveness, drug-resistance and the ability to form metastases at distant organs, and thereby contribute to cancer metastasis and relapse. Currently we still lack a coherent overview of the molecular and biochemical mechanisms inducing cells to enter various states along the epithelial-mesenchymal phenotypic spectrum. An improved understanding of the dynamic and plastic nature of the EMT program has the potential to yield novel therapies targeting this cellular program that may aid in the management of high-grade malignancies.
\end{abstract}

Keywords epithelial-to-mesenchymal transition; cancer; metastasis; cancer stem cell

\section{EMT: a naturally occurring transdifferentia- tion program}

\section{Basics of the EMT program}

The epithelial-to-mesenchymal transition (EMT) is a cellbiological program that naturally occurs in a broad range of tissue types and developmental stages. As its name implies, the EMT program converts epithelial cells to cells that have entered into more mesenchymal cell states arrayed along the epithelial (E) versus mesenchymal (M) axis. Depending on the contextual signals received by a cell within a tissue and the intracellular gene circuitry of the cell, this program generates cells that enter into a series of intermediate phenotypic states arrayed along the E-M axis and, when driven to its extreme, converts a fully epithelial cell to one residing in a fully mesenchymal cell state (Fig. 1A) [1]. Profound biological differences distinguish the extreme poles of the epithelial versus mesenchymal axis: the epithelial cells exhibit epithelial

Received April 6, 2018; accepted July 2, 2018

Correspondence: Yun Zhang, y.zhang@wi.mit.edu; Robert A. Weinberg, weinberg@wi.mit.edu cell-to-cell junctions and the apical-basal polarity, while the mesenchymal cells exhibit a heightened motility and invasiveness with spindle-like morphology that lacks apical-basal polarity [1,2].

Initially reported by Elizabeth Hay in 1982 [3], the EMT program is now known to have essential roles in multiple steps of embryonic morphogenesis $[1,4]$. This program operates during development to ensure the interconversions of cells that are required to form distinct cell types in metazoans. As examples, an EMT program gives rise to the mesoderm and primary mesenchyme from the primitive streak during gastrulation as well as to migratory neural crest cells. Disrupting this program in transgenic mice by silencing expression of certain transcription factors that orchestrate EMT programs (EMT-TFs), results in severe developmental defects [5-9]. Of note, while we refer here to "the EMT program", we also acknowledge that there are multiple versions of this program, depending on the EMT-TFs that are orchestrating this state change within a cell, the cell type in which it is occurring, and the microenvironment in which this cell resides.

In addition, the EMT program plays an essential role in various pathological processes, including wound healing, tissue fibrosis, and cancer progression $[1,10]$. In all of these 
A

Multiple intermediate states along the epithelial-mesenchymal spectrum

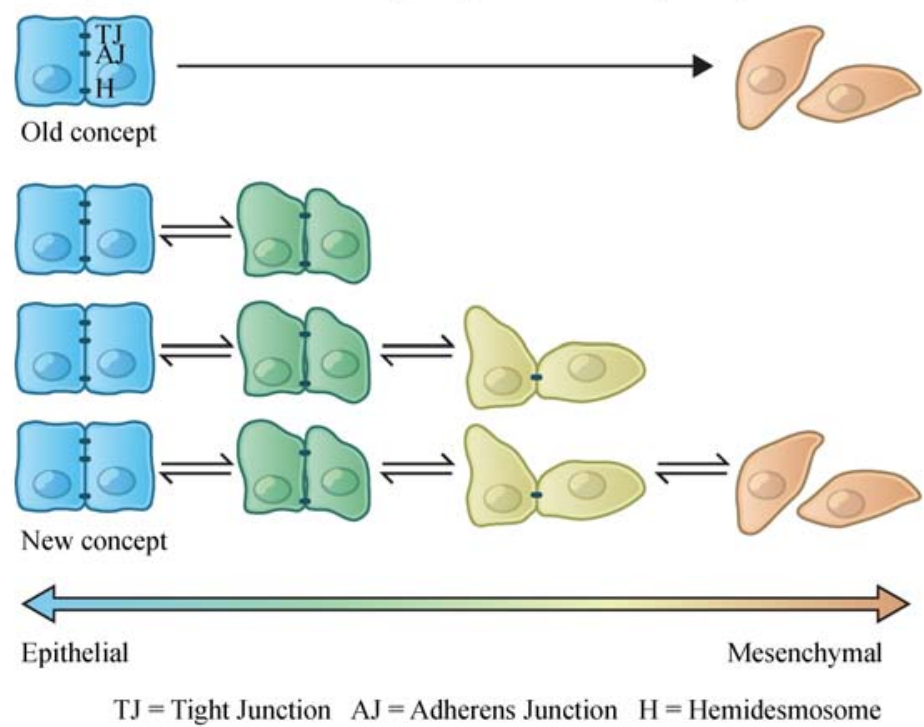

B

EMT and stemness

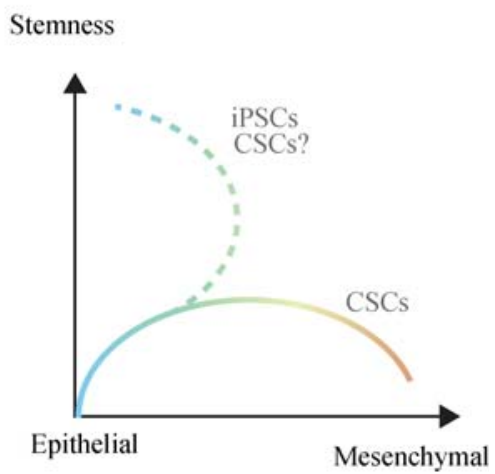

Fig. 1 The dynamic and plastic nature of the EMT program. (A) Rather than a unidirectional binary switch between two distinct cell states, accumulating evidence suggests that the epithelial-to-mesenchymal transition (EMT) program generates a spectrum of different intermediate cell states between the extreme epithelial and mesenchymal endpoints. (B) Activation of EMT program is associated with the entrance into stem cell programs, though in certain contexts, constitutive activation of an EMT program in carcinoma cells leads to the loss of stem-like properties. Cancer cells undergone a sequential EMT-MET reprogramming could be very different from the original epithelial cells in the primary tumor. When reprogramming somatic cells into induced pluripotent stem cells (iPSCs), sequential introduction of Yamanaka factors in a specific order (first OCT-4 with KLF4, then c-MYC, and finally SOX2), rather than the simultaneous exposure, has been found to significantly improve the reprogramming efficiency. In this specific protocol, a sequential EMT-MET state change has been observed, showing an intermediate state with upregulated EMT-TFs and enhanced mesenchymal characteristics before entering the epithelial pluripotent state [112]. It is plausible that a similar sequential EMT-MET transition could generate cancer cells with increased stemness and the ability to form macro-metastatic colonies.

processes, EMT and the reverse of this program, termed mesenchymal-to-epithelial transition (MET), induces multiple fundamental changes in cell physiology in addition to the morphologic differences noted above. For example, during epithelial wound healing, the viable epithelial cells at the edge of the wound site undergo a partial EMT in order to gain motility and move as a coordinated group of cells to help reconstruct the epithelial cell sheet. In the end, the quasi-mesenchymal cells created by the activation of an EMT program then revert to their epithelial phenotype through an MET to reestablish the epithelial sheet integrity [11]. Of note, in all of these pathological conditions, epithelial cells can activate the multifaceted EMT program to various extents, often acquiring many, but not all, of the traits associated with fully mesenchymal cells. Stated differently, under physiological conditions, epithelial cells activate an EMT program rarely if ever progress into an entirely mesenchymal cell state. Of note, EMT programs operate in both normal epithelial cells and their neoplastic derivatives.

The importance of EMT program in tumor progression has been established in the past two decades with a rapidly growing number of studies demonstrating the activation of EMT programs during the process of malignant progression $[1,10,12]$. In carcinomas, in which the contributions of the EMT program to cancer cell phenotypes have been most intensively studied, EMT-induced mesenchymal traits enable carcinoma cells to complete many of the steps of the invasion-metastasis cascade, including the local invasion of neoplastic cells at the primary tumor site, their intravasation into blood vessels, translocation through the circulation, extravasation into the parenchyma of distant tissues, and survival as micrometastatic deposits $[13,14]$. As noted above in the context of normal cells, it is also rare for carcinoma cells to lose all epithelial traits and gain a full spectrum of mesenchymal characteristics. An important though rare exception is provided by carcinosarcomas, in which distinct epithelial and mesenchymal compartments coexist and are derived from a common cellular precursor [15].

In addition, as described above in the context of normal epithelial cells, the EMT program is often activated reversibly, permitting the carcinoma cells to revert back to more epithelial states via MET, doing so in certain cellular contexts [16]. This plasticity of cell phenotypes may play an essential role in the last step of the metastatic cascade, the outgrowth of disseminated micrometastatic deposits into macroscopic metastases, the process termed colonization; as shown in mouse models and patientderived xenograft (PDX) models, activation of an EMT program is crucial for the dissemination of tumor cells, whereas the disseminated cells need to undergo MET in 
order to efficiently form macroscopic metastases [17-19]. Nonetheless, we note that successful colonization process may not be within the powers of the EMT program, but instead may depend on tissue-adaptive programs that disseminated cancer cells contrive after arriving in distant, unfamiliar tissue microenvironments. This dynamic and plastic nature of the EMT program during the progression of carcinomas should influence the interpretation of EMTassociated observations from both pre-clinical and clinical studies.

\section{EMT and stemness}

The concept of cancer stem cells (CSCs) in carcinomas is based on the observations that phenotypically distinct subpopulations of cancer cells coexist within a single tumor, with a small number of cancer cells showing certain similarities with non-neoplastic stem cells, including enhanced self-renewal and an ability to regenerate the entire neoplastic tumor tissue including more differentiated non-CSC derivatives $[10,20,21]$. In this paradigm, CSCs are hypothesized to play essential roles in continued tumor growth, metastasis initiation, drug resistance, and tumor relapse after therapy. An interesting but previously unanticipated aspect of the EMT program is its association with the entrance into epithelial stem cell programs (Fig. 1B) [22-24]. Since the initial discovery of the connection between breast cancer cells that have undergone an EMT and their entrance into a stem-cell like state [22,24], a number of studies have reported that acquisition of stemness following the activation of an EMT program in multiple cancer types including pancreatic, prostate, colorectal, ovarian cancer among other types of carcinomas [25-28].

A fact, we now know, at least in the context of mammary epithelial tissue, is that the association between EMT and stemness holds true for both normal and neoplastic conditions [22,23]. EMT-TF SLUG (also known as SNAI2) is expressed in the basal and/or abluminal layer of normal murine and human mammary ducts at sites where normal mammary stem cells are proposed to reside. (The functional assay for normal mammary stem cells involves implanting candidate mammary epithelial cells (MECs) into mammary fat pads from which the resident endogenous MECs have been surgically removed; stemness is judged by the ability of the implanted cells to generate entire mammary ductal trees after a number of weeks.) Forcing a population of normal MECs through an EMT, achieved via transiently expressing SLUG and SOX9, dramatically increased the representation of mammary stem cells within the heterogeneous populations of MECs. Conversely, shutdown of SLUG in MECs deprives them of their mammary gland-reconstituting activity, indicating a causal role of this EMT-TF in the entrance into and/or maintenance of the stem cell state
[23]. In parallel experiments, forcing bulk populations of human breast cancer cells through an EMT program by transient expression of EMT-TFs can increase the frequency of tumor-initiating $\mathrm{CSCs}$, as shown by the increased expression of CSC-specific cell-surface markers, an elevated ability to form tumorspheres in suspension culture, and an elevated ability to initiate tumors in immuno-compromised mice [22]. It is still unclear precisely how different the EMT-induced stem cell programs are between the non-neoplastic cells and their corresponding neoplastic cells. However, we now know that in mammary gland, normal gland-reconstituting stem cells and breast CSCs depend on the actions of the related EMT-TFs Slug and Snail, respectively, suggesting that the stem-cell programs operating in CSCs and normal stem cells of the corresponding normal tissue are likely to differ significantly in their details [29].

The association between the EMT program and the CSC state, as described above, suggests that, in general, activation of this program in non-CSCs enables their conversion into CSCs. Indeed, populations of non-CSC have been shown to spontaneously undergo EMT under appropriate conditions, acquiring CSC-like cell-surface markers and an enhanced capacity to seed tumors in mice [30,31]. The resulting CSCs, because of their functioning as stem cells, have the ability to generate more differentiated non-CSC derivatives, possibly through the activation of an MET. Of note, the substantial phenotypic plasticity between non-CSCs and CSCs, determined by the dynamic and plastic nature of the EMT program during cancer progression, suggests that in neoplastic tissues, a unidirectional stem-cell hierarchy does not apply. Instead, a description of bidirectional interconversions involving phenotypic shifts between distinct cellular states appears to be more appropriate.

It remains unclear precisely how EMT programs facilitate the entrance of both normal and neoplastic epithelial cells into stem cell states. Independent of this issue is a second one: where do stem cells reside along the spectrum of phenotypic states that ranges from fully epithelial to fully mesenchymal? Several recent studies reported that in certain contexts, constitutive activation of an EMT program in carcinoma cells leads to the loss of stem-like properties, suggesting that the acquisition of mesenchymal traits is not always associated with the acquisition of increased stemness $[17,18,32]$. Several possible explanations of this observation are worthy of further exploration: (1) expression of certain transcription factors or other types of gene regulators, similar to Sox9 in differentiated mammary luminal/myoepithelial cells, might be required in order to coordinate an EMT program that leads cells into stem cell states; (2) stemness and mesenchymal traits may represent two mutually exclusive sets of cellular characteristics; (3) stemness is only associated with residence in certain intermediate transition 
states along the E-M axis, dictating that only those cells that express certain combinations of epithelial and mesenchymal traits acquire stem-like properties [33].

\section{EMT in cancer progression}

\section{EMT and metastasis}

Metastasis remains the most life-threatening risk for cancer patients, with more than $90 \%$ of cancer-associated deaths being caused by metastatic disease rather than by the corresponding primary tumors $[13,34]$. The increased motility/invasiveness associated with the mesenchymal cell state has linked the EMT program with metastasis, in which cell separation from the primary tumor mass can be considered as the first step of the invasion-metastasis cascade. Thus, a variety of studies using both mouse models and cultured human cancer cells have demonstrated that induction of an EMT program allows carcinoma cells to lose cell-cell junctions, degrade local basement membrane via elevated expression of various matrix-degrading enzymes, and thus support their migration and invasion as single cells (Fig. 2A) [17,18,35,36]. In an alternative mode of cancer cell invasion, cohorts of cells, rather than single cells, migrate together into adjacent tissues. In fact, this "collective migration" mode might be even more frequent than single-cell dissemination in clinical tumors, as supported by several recent studies showing the polyclonal nature of many invasive/metastatic colonies [37-40]. Although cells residing within the bulk of these invasive masses usually maintain cell-cell junction and express E-cadherin, the prototypical marker of epithelial cell state, detailed analyses of these invasive cohorts suggest that carcinoma cells at the leading edges of these invasive masses often express certain mesenchymal characteristics, supporting the notion in which invading leader cells undergo EMT to gain motility and release various proteases to degrade the extracellular matrix, doing so in order to pave the way for all the more epithelial follower cells (Fig. 2A) [29,41-43]. In addition, Ecadherin has been reported to exist in functionally distinct complexes within the same cell [44], though it remains unclear how these different complexes contribute to cancer progression and whether an EMT program regulates the switch of E-cadherin between these complexes. At present, key experimental tests to demonstrate the essentiality of EMT for invasiveness, which would depend on completely blocking this program and demonstrating continued invasion, have not yet been produced.

In addition to local invasiveness, the association between EMT and entrance into the CSC state suggests that this program could also contribute to additional steps in the invasion-metastasis cascade. Thus, the possession of tumor-initiating powers of CSCs would seem to be a critical prerequisite to the founding by disseminated cancer cells of metastatic colonies. Many circulating tumor cells (CTCs), representing carcinoma cells that have invaded into the vasculature (intravasated) and may thereafter be capable of seeding new metastatic colonies at distant anatomical sites, display partial EMT activation with coexpression of both epithelial and mesenchymal markers (Fig. 2B) [45]. Of note, in many of the published analyses of CTCs, the enrichment methods that were employed were based on the display of certain epithelial cell-surface markers such as EpCAM, and thus may fail to capture cancer cells that have proceeded more extensively through the EMT program, causing them to lose the bulk of their epithelial cell-surface markers. In any event, only rare cells among the CTCs may eventually serve as the founders of metastatic colonies because of the profound inefficiency of the post-dissemination colonization process [13].

Disseminated cancer cells, which have traveled to distant sites and invaded the parenchyma of various tissues, may initially enter into a dormant state due to their inability to adapt to a newly encountered tissue microenvironment. The behavior of disseminated cancer cells is of great interest because such cells can potentially proceed to form macroscopic metastatic colonies, the most deadly phase of malignant cancer progression, but this represents a high barrier to successful colonization and might provide a therapeutic time window to manage metastatic disease. Following extravasation, disseminated tumor cells almost always become eliminated or, alternatively, enter a state of dormancy in the ostensibly inhospitable newly encountered tissue microenvironment [46-48]. In clinical practice, patients successfully treated for their primary tumors may often harbor disseminated cancer cells residing in a dormant state in various organs throughout the body. This apparent dormancy may result from their inability to proliferate in their new microenvironments or, alternatively, they may exhibit a low proliferation rate in which any increases in the number of carcinoma cells is counterbalanced by continued immune attacks [49]. Although it is difficult to rigorously prove that metastatic colonies are directly developed from these dormant disseminated cells, the presence of dormant tumor cells in the bone marrow has been found to correlate significantly with clinical recurrence in breast cancer patients [50]. In addition, in both mouse models and patient samples, the expression of EMT-associated traits and the systemic dissemination of cancer cells have been found to begin early in the disease course, being evident even in certain pre-neoplastic lesions [29,51-53]. These findings indicate that it is of great clinical importance to eliminate these dormant cancer cells or to prevent their development into macro-metastases.

Interestingly, it seems clear that the robust outgrowth of metastatic colonies, at least in some destination organ sites, requires the plasticity between $\mathrm{E}$ versus $\mathrm{M}$ states rather than constitutive residence in a fully mesenchymal state 


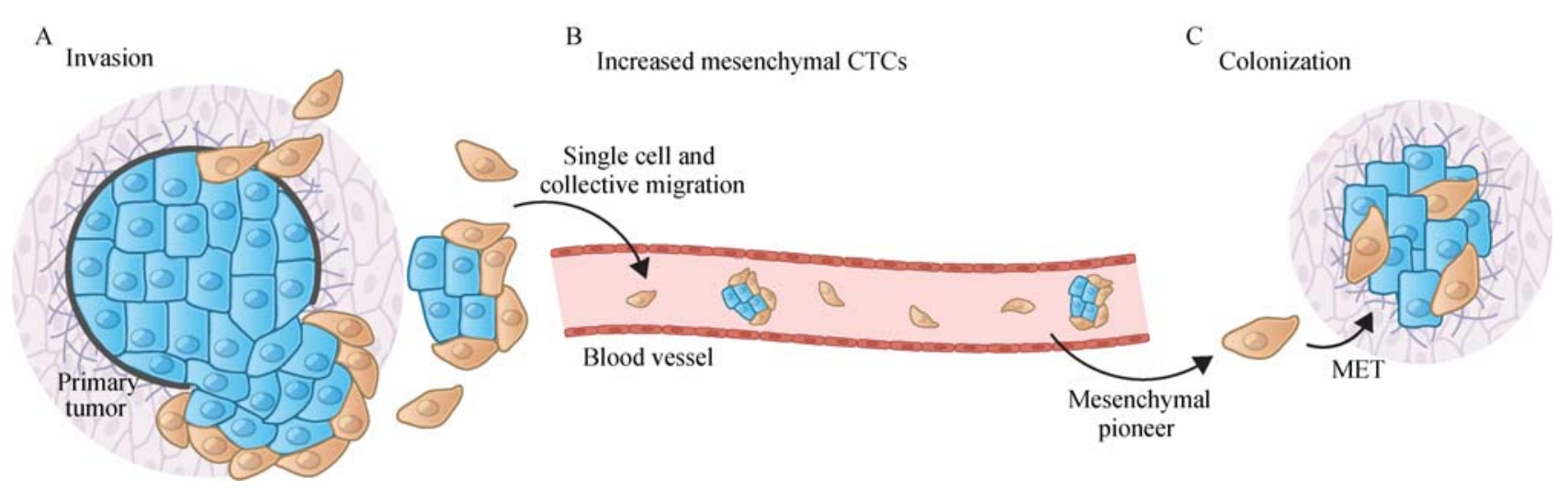

Fig. 2 The EMT program facilitates multiple steps of the invasion-metastatic cascade. (A) At the primary tumor site, induction of an EMT program allows carcinoma cells to lose cell-cell junctions, degrade local basement membrane via elevated expression of various matrix-degrading enzymes and supports cancer cell dissemination in both the "single cell" and "collective migration" modes. (B) Many circulating tumor cells (CTCs), representing carcinoma cells that have entered into the vasculature and may thereafter be capable of seeding new metastatic colonies at distant anatomical sites, display partial EMT activation with co-expression both epithelial and mesenchymal markers. Moreover, mesenchymal CTCs have been found to be significantly enriched in cancer patients with refractory or progressive disease [45]. (C) At the colonization step, robust outgrowth of macro-metastases, at least in some destination organ sites, requires the reversion of EMT program and the associated gain of epithelial characteristics.

(Fig. 2C). For example, studies using mouse models of breast and skin cancers have demonstrated that activation of an EMT program is important for primary tumor cells to disseminate into the lungs, while the disseminated cells need to subsequently reverse the EMT program and gain epithelial characteristics in order to efficiently form macroscopic metastases [17,18]. Similar observations have been made in mouse models of pancreatic cancer where cancer cells form metastases in the liver [54]. It remains unclear why the formation of macrometastases seemingly founded by more mesenchymal pioneers requires the subsequent generation by these pioneers of more epithelial progeny. Nonetheless, we note that restoration of the full epithelial traits is not necessary for all types of metastases, as shown in most cases of invasive lobular carcinoma of the breast, in which E-cadherin expression is completely lost due to $\mathrm{CDH} 1$ mutation but macrometastases can still be formed [55].

\section{EMT contributes to tumor heterogeneity}

The phenotypic diversity of neoplastic cells within a tumor is increasingly considered as a major obstacle to the success of cancer therapies [56-59]. Both genetic and epigenetic mechanisms contribute to phenotypic heterogeneity within individual tumors. With recent advances in next-generation sequencing technologies, the impact and influence of genetic heterogeneity in designing effective treatment strategies have been widely recognized and extensively discussed [60]. Still, the ability of cancer cells with the same genetic profile to interconvert between multiple distinct phenotypic states via epigenetic regulatory mechanisms, thereby contributing to critical cancer cell behaviors, has not been fully understood.

The ability of the EMT program in generating invasive mesenchymal cells and CSCs represents an important example how epigenetic mechanisms contribute to forming tumor heterogeneity. Similarly, expression of oncogenic mutant PIK3CA ${ }^{\mathrm{H} 1047 \mathrm{R}}$ in mouse mammary epithelial cells has been shown to evoke cell dedifferentiation into a multipotent stem-like state and thereby facilitate the formation of a heterogeneous, multi-lineage mammary tumor [61]. However, it remains unclear whether this program has any connections with the EMT-induced stem cell programs. In another example, loss of RB1 and TP53 function in prostate adenocarcinomas enables lineage plasticity of androgen receptor (AR)-dependent luminal epithelial cells, allowing them to shift into AR-independent basal-like cells, and thus gain resistance to targeted antiandrogen drugs $[62,63]$. In both cases, certain mutant oncogenes or loss of tumor suppressors induce cancer cell plasticity, generating different daughter cells at the epigenetic level with distinct cellular behaviors in drug resistance, tumor initiation and metastasis. A number of intermediate EMT states have also been identified in transgenic mouse models of skin squamous cell carcinoma and breast cancer. These EMT subpopulations coexist in the primary tumor but display differences in their invasiveness and metastatic potentials [64]. All these examples reveal the critical need to further explore these plasticity mechanisms in the context of cancer in order to develop effective anti-cancer therapies in the future.

\section{EMT confers therapeutic resistance}

EMT programs increase the resistance to cell death induced through various mechanisms both in embryos and in cancer cells. For example, accumulating evidence indicates that activation of EMT confers multidrug resistance on cancer cells $[10,65]$. Similar to certain non- 
neoplastic tissue stem cells that exhibit higher levels of resistance to multiple chemotherapeutic agents, EMTinduced multidrug resistance involves a number of mechanisms, including a slow proliferation rate, elevated expression of anti-apoptotic proteins, and upregulation of ATP binding cassette (ABC) transporters that mediate drug efflux (Fig. 3A) [66-68]. In addition, the E-to-M transition may be associated with entrance into novel phenotypic states, which explains, in turn, the acquired resistance to many targeted therapies once the therapeutic targets become dispensable for continued cell viability. For example, in non-small-cell lung cancer (NSCLC) and ovarian cancer, the E-to-M transition switches the dependence of carcinoma cells from the EGFR to the AXL receptor tyrosine kinase, thereby yielding resistance to EGFR-targeted therapy (Fig. 3B) [69,70]. Moreover, the survival of relatively slow-cycling subpopulations of carcinoma cells may allow certain partially mesenchymal cancer cells to accumulate additional genetic mutations, ultimately generating highly proliferative descendants exhibiting acquired phenotypic advantages such as drug resistance. Indeed, several recent studies have shown the existence of such epigenetically driven, drug-tolerant cell states with enriched EMT signatures [71,72]. In one particular study, a mesenchymal drug-tolerant state has been observed to function as an important intermediate stage, enabling initially- $E G F R^{\mathrm{T} 790 \mathrm{M}}$-negative non-smallcell lung cancer cells to acquire this "gatekeeper" mutation following treatment with EGFR inhibitors [71].

Recent studies also suggest that the EMT program contributes to the establishment of an immunosuppressive tumor microenvironment and thereby confers resistance to immunotherapies (Fig. 3C) [73]. EMT-mediated resistance to immunotherapies seems to be acquired through both cell-autonomous and non-autonomous mechanisms. From the perspective of cancer cells, induction of an EMT program in carcinoma cells has been shown to reduce susceptibility to cytotoxic T cell-mediated lysis, possibly due to the reduced vulnerability to apoptosis in quasimesenchymal cell states [74,75]. Consistently, naturally arising mesenchymal cells from MMTV-PyMT mouse mammary tumor model have been found to express markedly lower levels of MHC-I molecules and $\beta 2$ microglobulin compared with their epithelial counterparts, yielding an immunoevasive phenotypic state [76]. In lung and breast carcinoma cells, upregulation of the ZEB1 EMT-TF has been shown to induce the expression of PDL1, an immune-inhibitory checkpoint ligand that suppresses the function of activated $T$ cells through binding to its cognate PD-1 receptor expressed by the latter [77,78].

In addition, induction of EMT has been shown to remodel the tumor microenvironment, helping to convert it into an immunosuppressive state (Fig. 3C). Thus, Snailinduced EMT in melanoma cells has been shown to increase the infiltration of immunosuppressive regulatory $\mathrm{T}$ cells in the tumor microenvironment, partly through an increased secretion of TGF- $\beta$ and thrombospondin- 1 by the quasi-mesenchymal cancer cells [79]. Similar observations have been reported in breast cancer models in which tumors initiated from more epithelial MMTV-PyMT carcinoma cells contained more M1 (anti-tumor) macrophages and $\mathrm{CD}^{+} \mathrm{T}$ cells. In contrast, tumors arising from more mesenchymal cells contained more regulatory $\mathrm{T}$ cells and M2 (pro-tumorigenic) macrophages. At the same time, these tumors contained fewer $\mathrm{CD} 8^{+} \mathrm{T}$ cells, most of which showed markers of functional exhaustion. Importantly, in
A

Drug resistance

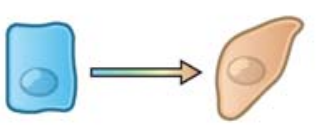

$\downarrow$ Slower proliferation

$\uparrow$ Anti-apoptotic proteins

$\uparrow \mathrm{ABC}$ transporters
B

Gene-network rewiring

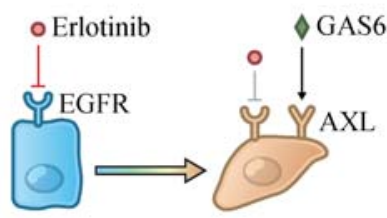

C Resistance to immunotherapies

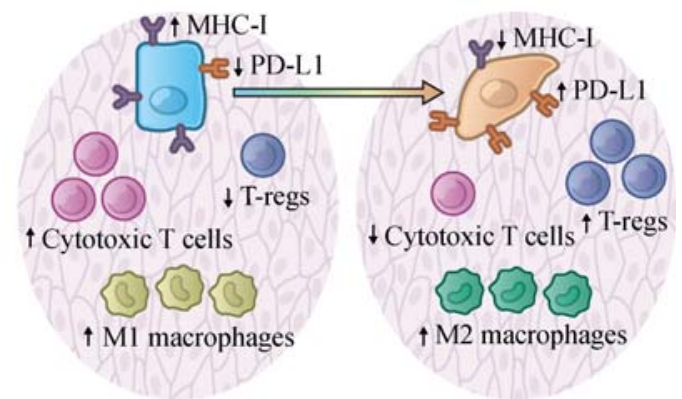

Fig. 3 EMT confers therapeutic resistance. (A) EMT confers multidrug resistance on cancer cells. EMT-induced multidrug resistance involves a number of mechanisms, including a slow proliferation rate, elevated expression of anti-apoptotic proteins, and upregulation of ATP binding cassette $(\mathrm{ABC})$ transporters that mediate drug efflux. (B) The E-to-M transition may induce cancer cells into novel phenotypic states and make certain therapeutic targets dispensable for continued cell viability. For example, the E-to-M transition switches the dependence of carcinoma cells from the EGFR to the AXL receptor tyrosine kinase in non-small-cell lung cancer cells, thereby yielding resistance to EGFR-targeted therapy. (C) The EMT program contributes to the establishment of an immunosuppressive tumor microenvironment and confers resistance to immunotherapies. In a cell-autonomous manner, induction of EMT program in carcinoma cells downregulates MHC-I molecules and $\beta 2$-microglobulin while upregulating PD-L1. In addition, induction of EMT program leads to various non-cell-autonomous changes, remodeling the tumor microenvironment by recruiting M2 (pro-tumorigenic) macrophages and Tregs, and suppressing the infiltration of cytotoxic T cells. 
this breast cancer model, a minority of quasi-mesenchymal cancer cells within a tumor were able to induce the immunosuppressive microenvironment and protect the more epithelial cancer cells residing in the same tumor from immune attack [76]. These studies highlight the critical need to acquire further insights into the influences of EMT programs on modulating tumor microenvironment.

In summary, these diverse observations help to explain how EMT-induced CSCs can serve as a cell population that limits the efficacy of currently employed anticancer therapies. It is highly plausible that many therapeutic regimens largely target the bulk populations of more epithelial non-CSCs, while being unable to eliminate the minority subpopulations of CSCs. In the context of immunotherapy, an EMT-induced immunosuppressive tumor microenvironment may protect not only the mesenchymal CSCs but also epithelial non-CSCs. Moreover, the surviving CSCs, given their tumor-initiating capacity, may be able to initiate new tumors, eventually leading to clinical relapse.

\section{Complexity of the epithelial-mesenchymal phenotypic spectrum}

During the multistep tumor progression of carcinomas, EMT programs operate in cells residing both at the very beginning stages of this process (involving normal epithelial cells), and the final stage (involving fully malignant carcinoma cells). These observations suggest that a core EMT program also participates in all the cell populations existing in the intermediate stages of multistep tumor progression, i.e., cell populations lying between these two endpoints. This core EMT program might collaborate with other cellular programs to generate a spectrum of distinct cell-biological states along the $\mathrm{E}$ versus $M$ axis. These intermediate cell states, displaying distinct cellular behaviors, such as differing powers of invasiveness and drug resistance, may facilitate cancer cell proliferation and dissemination occurring at different stages of tumor progression [64]. These complex behaviors suggest a variety of alternative versions of the EMT program, and conversely complicate attempts to rationalize cancer cell behavior during multi-stage progression in terms of a single, uniformly expressed EMT program.

Indeed, several dimensions of complexity contribute to the phenotypic heterogeneity generated by the EMT program. First, although the EMT program is executed by a relatively small number of master regulators, e.g., the SNAIL, TWIST, SLUG and ZEB1 EMT-TFs; these proteins, acting in various combinations, are not equally potent in repressing epithelial properties and inducing mesenchymal features $[80,81]$. In addition, they display many non-redundant functions. For example, as mentioned above, while SLUG plays an essential role in maintaining stemness in normal gland-reconstituting mammary stem cells, SNAIL is the EMT-TF that is utilized in breast cancer cells to generate CSCs and trigger metastasis [29]. Second, different developmental origins may dictate distinct responses to expressed EMT-TFs, yielding entrance into diverse phenotypic states arrayed along the $\mathrm{E}$ versus $\mathrm{M}$ spectrum. Accordingly, the same EMT-TF may elicit distinct cellular responses in different carcinoma types. In support of this notion, despite the observation that SNAIL is critical for promoting metastasis in the PyMT mouse model of breast cancer, this particular EMT-TF seems to be dispensable for metastasis in the KPC mouse pancreatic cancer model $[29,82,83]$. Interestingly, ZEB1 has been shown to operate as a key factor driving metastasis in the latter model [36]. Third, activation of EMT programs is induced by converging heterotypic signals in vivo. Given the heterogeneous cellular microenvironment within a tumor, individual cancer cells in various locations may reside at different distances from signal-emitting stromal cells, encounter different levels of EMT-inducing cytokines, and experience different degrees of hypoxia [84]. These different combinations of contextual signals might induce cancer cells to enter distinct EMT intermediate states along the E-M axis. Among other implications, this suggests topological localization of EMT-induced traits within individual tumors. For example, by analyzing headand-neck squamous cell carcinomas at the single-cell level, cells with partial EMT features have been found to spatially localize to the leading edge of primary tumors and facilitate invasion [43].

At the mechanistic level, we still lack coherent understanding of the molecular and biochemical mechanisms inducing cells to enter various states arrayed along the epithelial-mesenchymal phenotypic spectrum. We do know that a complex regulatory network that orchestrates EMTs and modulates the expression and function of EMTTFs at multiple mechanistic levels, including transcription, post-transcription, epigenetic modification, alternative splicing, protein stability and subcellular localization $[1,81]$. For example, the EMT-TFs ZEB1 and SNAIL form double-negative feedback loops with miR-200 and miR-34, respectively, which is thought to maintain epithelial homeostasis under physiological conditions [85-88]. Several transcription factors, including ELF5, GRHL2, OVOL1/2 and p53, have also been found to function as "guardians of the epithelial phenotype" in certain contexts by suppressing the expression of specific EMT-TFs [89-92]. In addition, cells residing in epithelial and mesenchymal states display distinct RNA splicing programs [93]. Some of the splicing factors, such as ESRP 
family members, are associated with the epithelial phenotype and regulate production of key transcripts whose encoded products are involved cell-cell adhesion, cell-matrix adhesion, and invasion [94]. Other splicing factors, like QKI and RBFOX2, are found to be upregulated in the more mesenchymal cell state and suppress epithelial properties $[95,96]$. Several chromatin modifiers, including HDAC1/2, LSD1 and components of PRC2 complex, are recruited by certain EMT-TFs to their target promoters. These epigenetic regulators are plausibly involved in forming epigenetic regulatory loops, that may control the interconversions between different intermediate EMT states [97-99]. In addition, at the protein level, ubiquitin-mediated degradation and phosphorylationinduced subcellular localization of EMT-TFs have been shown to regulate the EMT process. The ubiquitin ligases and phosphatases participating in this process can be induced by a variety of intracellular signaling channels, such as those involving the WNT, MAPK and DNA damage pathways $[100,101]$. In addition, the establishment and maintenance of mesenchymal/CSC states require specific contextual signals and distinct intermediate EMT states are plausibly maintained in different niches within the tumor microenvironment. For example, TGF- $\beta$ has been shown to induce EMT and maintain the mesenchymal cell state in many cell systems and the mechanisms explaining how TGF- $\beta$ activates the EMT program have been reviewed elsewhere [102]. However, induction of EMT by TGF- $\beta$ appears to need an appropriate intracellular context and thus is not universal for all the cell types or cell states [103]. A mesenchymal/CSC state can also be maintained by a juxtacrine signaling from monocytes and macrophages, or by prostaglandin $\mathrm{E}_{2}\left(\mathrm{PGE}_{2}\right)$ secreted from mesenchymal stem cells $[104,105]$. It remains to be determined whether these mechanisms are also functional in vivo, and whether the mesenchymal/CSC state generated through these mechanisms represent discrete intermediate states arrayed along the epithelial-mesenchymal axis.

All this explains the ongoing need to construct a systematic framework of EMT regulation in order to incorporate these diverse mechanisms into a single overarching scheme. Such a scheme will lay the foundation for answering four major categories of questions: (1) In a particular cancer type, how many intermediate phenotypic states exist between the fully epithelial and the fully mesenchymal states? Are these different phenotypic EMT states shared among different cancer types? (2) What genes constitute the core gene circuit in each of these intermediate states? Can residence in these metastable phenotypic states be maintained over multiple cell generations? Do the E-to-M conversion requires a cell division? (3) For each of these EMT states, which specific extracellular signals are sufficient to induce metastable residence of carcinoma cells in these multiple alternative phenotypic states? (4) What are the precise functional contributions of these intermediate states to the multistep cancer progression?

\section{Concluding remarks and future directions}

Major conceptual advances about the EMT program in cancer progression have provided us with new insights into the biological basis of tumor malignancy, including (1) the role of EMT programs in promoting cancer cell dissemination in both "single cell migration" and "collective migration" models, (2) the connection between EMT program and the CSC state, and (3) the contribution of EMT programs to the acquired resistance to chemo- and immuno-therapies. Recent findings have highlighted the dynamic and plastic nature of the EMT program, suggesting the existence of diverse phenotypic cell states arrayed along the E-to-M spectrum. Nonetheless, we still lack a systematic framework to identify all the states orchestrated by EMT programs and the responsible intracellular control circuits. Future research will be needed to explore these cell-biological programs at a higher resolution, ideally at the single-cell level, doing so in order to generate a complete map of all the intermediate cell states between the two end points of the $\mathrm{E}$ to $\mathrm{M}$ axis. In addition, to fully understand the functional contribution of EMT programs in cancer metastasis and relapse, it will be necessary to develop more sophisticated mouse models that enable real-time monitoring of the residence of cancer cells in various EMT-induced states and/or lineage-tracing of the cancer cells that have entered certain EMT states during the course of tumor development.

Given the pleiotropic roles of the EMT program in the invasion-metastasis cascade and the acquisition of therapeutic resistance, the development of novel therapies targeting this cellular program is clearly desirable. Theoretically, at least three strategies for targeting this program seem worthy of further exploration:

(1) Specifically targeting cancer cells that have undergone EMT and display mesenchymal/CSC features. Along this line, the receptor tyrosine kinase AXL has been found to associate with EMT induction and confers resistance to EGFR-targeted therapy in a cohort of NSCLC patients [70]. When treated with both EGFR and AXL inhibitors, NSCLC cells could no longer develop the EMT-induced resistance to treatment by erlotinib (an EGFR inhibitor) in a mouse xenograft model [70]. The first AXL-specific inhibitor, BGB324, has entered clinical trials recently $[106,107]$. In addition, two recent studies demonstrated that the mesenchymal cell state depends on a druggable lipid-peroxidase pathway in a variety of cancer types. Inhibition of GPX4, a selenocysteine-containing enzyme that plays a central role in this pathway, induces ferroptotic cell death specifically in mesenchymal cell populations $[108,109]$. 
(2) Reverse the process of EMT at certain stages of tumor development by differentiation-inducing therapies. For example, cholera toxin and forskolin have been found to enhance protein kinase A signaling, triggering the process of MET and thus reducing the invasiveness and tumor-initiating abilities of mammary tumor cells [110]. The clinical implementation of this strategy needs to be designed with great care, in light of the fact that the MET process may actually promote colonization, the last step of the invasion-metastasis cascade.

(3) Inhibiting the plasticity of cancer cells and preventing the EMT induction. EMT can be prevented by targeting the signaling processes that induce and subsequently maintain certain mesenchymal states. From this perspective, TGF- $\beta$ inhibitors are the most intensively investigated anti-EMT compounds. One particular TGF- $\beta$ inhibitor, termed LY2157299, has entered clinical trial recently [111]. However, it should be noted that TGF- $\beta$ has multifaceted effects on cancer cells in a context-dependent manner. Thus it remains to be determined which particular clinical indications suggest implementation of this treatment. Nonetheless, while the current therapeutic strategies targeting the EMT program are still rudimentary, this overall direction represents an attractive avenue for the future development of truly effective therapies designed to manage high-grade tumor malignancies.

\section{Acknowledgements}

We would like to thank all members of the R.A.W. laboratory for fruitful discussions and especially Arthur W. Lambert for critical review of the manuscript. We would also like to thank Meredith Leffler for preparation of the figures. Y.Z. is supported by Susan G. Komen Postdoctoral Fellowship (No. PDF15301255). Work in the R.A.W. laboratory is supported by grants from the NIH (No. R01CA078461), the Breast Cancer Research Foundation, the Advanced Medical Research Foundation, and the Ludwig Center for Molecular Oncology. R.A.W. is an American Cancer Society Research Professor and a Daniel K. Ludwig Cancer Research Professor.

\section{Compliance with ethics guidelines}

Yun Zhang and Robert A. Weinberg declare no competing interests. This manuscript is a review article and does not involve a research protocol requiring approval by the relevant institutional review board or ethics committee.

Open Access This article is distributed under the terms of the Creative Commons Attribution 4.0 International License (http:// creativecommons.org/licenses/by/4.0/), which permits unrestricted use, distribution, and reproduction in any medium, provided the appropriate credit is given to the original author(s) and the source, and a link is provided to the Creative Commons license, which indicates if changes are made.

\section{References}

1. Nieto MA, Huang RYJ, Jackson RA, Thiery JP. EMT: 2016. Cell 2016; 166(1): 21-45

2. Polyak K, Weinberg RA. Transitions between epithelial and mesenchymal states: acquisition of malignant and stem cell traits. Nat Rev Cancer 2009; 9(4): 265-273

3. Greenburg G, Hay ED. Epithelia suspended in collagen gels can lose polarity and express characteristics of migrating mesenchymal cells. J Cell Biol 1982; 95(1): 333-339

4. Lim J, Thiery JP. Epithelial-mesenchymal transitions: insights from development. Development 2012; 139(19): 3471-3486

5. Carver EA, Jiang R, Lan Y, Oram KF, Gridley T. The mouse snail gene encodes a key regulator of the epithelial-mesenchymal transition. Mol Cell Biol 2001; 21(23): 8184-8188

6. Chen ZF, Behringer RR. twist is required in head mesenchyme for cranial neural tube morphogenesis. Genes Dev 1995; 9(6): 686699

7. Van de Putte T, Maruhashi M, Francis A, Nelles L, Kondoh H, Huylebroeck D, Higashi Y. Mice lacking ZFHX1B, the gene that codes for Smad-interacting protein-1, reveal a role for multiple neural crest cell defects in the etiology of Hirschsprung diseasemental retardation syndrome. Am J Hum Genet 2003; 72(2): 465470

8. Jiang R, Lan Y, Norton CR, Sundberg JP, Gridley T. The Slug gene is not essential for mesoderm or neural crest development in mice. Dev Biol 1998; 198(2): 277-285

9. Higashi Y, Moribe H, Takagi T, Sekido R, Kawakami K, Kikutani $\mathrm{H}$, Kondoh H. Impairment of T cell development in $\delta \mathrm{EF} 1$ mutant mice. J Exp Med 1997; 185(8): 1467-1479

10. Shibue T, Weinberg RA. EMT, CSCs, and drug resistance: the mechanistic link and clinical implications. Nat Rev Clin Oncol 2017; 14(10): 611-629

11. Shaw TJ, Martin P. Wound repair: a showcase for cell plasticity and migration. Curr Opin Cell Biol 2016; 42: 29-37

12. Ye X, Weinberg RA. Epithelial-mesenchymal plasticity: a central regulator of cancer progression. Trends Cell Biol 2015; 25(11): 675-686

13. Lambert AW, Pattabiraman DR, Weinberg RA. Emerging biological principles of metastasis. Cell 2017; 168(4): 670-691

14. Thiery JP. Epithelial-mesenchymal transitions in tumour progression. Nat Rev Cancer 2002; 2(6): 442-454

15. Thompson L, Chang B, Barsky SH. Monoclonal origins of malignant mixed tumors (carcinosarcomas). Evidence for a divergent histogenesis. Am J Surg Pathol 1996; 20(3): 277-285

16. Tsai JH, Yang J. Epithelial-mesenchymal plasticity in carcinoma metastasis. Genes Dev 2013; 27(20): 2192-2206

17. Ocaña OH, Córcoles R, Fabra A, Moreno-Bueno G, Acloque H, Vega S, Barrallo-Gimeno A, Cano A, Nieto MA. Metastatic colonization requires the repression of the epithelial-mesenchymal transition inducer Prrx1. Cancer Cell 2012; 22(6): 709-724

18. Tsai JH, Donaher JL, Murphy DA, Chau S, Yang J. Spatiotemporal regulation of epithelial-mesenchymal transition is essential for squamous cell carcinoma metastasis. Cancer Cell 2012; 22(6): 725-736

19. Lawson DA, Bhakta NR, Kessenbrock K, Prummel KD, Yu Y, Takai K, Zhou A, Eyob H, Balakrishnan S, Wang CY, Yaswen P, 
Goga A, Werb Z. Single-cell analysis reveals a stem-cell program in human metastatic breast cancer cells. Nature 2015; 526(7571): 131-135

20. Pattabiraman DR, Weinberg RA. Tackling the cancer stem cells - what challenges do they pose? Nat Rev Drug Discov 2014; 13(7): 497-512

21. Brabletz T, Jung A, Spaderna S, Hlubek F, Kirchner T. Opinion: migrating cancer stem cells - an integrated concept of malignant tumour progression. Nat Rev Cancer 2005; 5(9): 744-749

22. Mani SA, Guo W, Liao MJ, Eaton EN, Ayyanan A, Zhou AY, Brooks M, Reinhard F, Zhang CC, Shipitsin M, Campbell LL, Polyak K, Brisken C, Yang J, Weinberg RA. The epithelialmesenchymal transition generates cells with properties of stem cells. Cell 2008; 133(4): 704-715

23. Guo W, Keckesova Z, Donaher JL, Shibue T, Tischler V, Reinhardt F, Itzkovitz S, Noske A, Zürrer-Härdi U, Bell G, Tam WL, Mani SA, van Oudenaarden A, Weinberg RA. Slug and Sox 9 cooperatively determine the mammary stem cell state. Cell 2012; 148(5): 1015-1028

24. Morel AP, Lièvre M, Thomas C, Hinkal G, Ansieau S, Puisieux A. Generation of breast cancer stem cells through epithelialmesenchymal transition. PLoS One 2008; 3(8): e2888

25. Rasheed ZA, Yang J, Wang Q, Kowalski J, Freed I, Murter C, Hong SM, Koorstra JB, Rajeshkumar NV, He X, Goggins M, Iacobuzio-Donahue C, Berman DM, Laheru D, Jimeno A, Hidalgo M, Maitra A, Matsui W. Prognostic significance of tumorigenic cells with mesenchymal features in pancreatic adenocarcinoma. J Natl Cancer Inst 2010; 102(5): 340-351

26. Kong D, Banerjee S, Ahmad A, Li Y, Wang Z, Sethi S, Sarkar FH. Epithelial to mesenchymal transition is mechanistically linked with stem cell signatures in prostate cancer cells. PLoS One 2010; 5(8): e12445

27. Fan F, Samuel S, Evans KW, Lu J, Xia L, Zhou Y, Sceusi E, Tozzi F, Ye XC, Mani SA, Ellis LM. Overexpression of snail induces epithelial-mesenchymal transition and a cancer stem cell-like phenotype in human colorectal cancer cells. Cancer Med 2012; 1 (1): 5-16

28. Long H, Xiang T, Qi W, Huang J, Chen J, He L, Liang Z, Guo B, $\mathrm{Li}$ Y, Xie R, Zhu B. CD133 ${ }^{+}$ovarian cancer stem-like cells promote non-stem cancer cell metastasis via CCL5 induced epithelial-mesenchymal transition. Oncotarget 2015; 6(8): 58465859

29. Ye X, Tam WL, Shibue T, Kaygusuz Y, Reinhardt F, Ng Eaton E, Weinberg RA. Distinct EMT programs control normal mammary stem cells and tumour-initiating cells. Nature 2015; 525(7568): 256-260

30. Chaffer CL, Brueckmann I, Scheel C, Kaestli AJ, Wiggins PA, Rodrigues LO, Brooks M, Reinhardt F, Su Y, Polyak K, Arendt LM, Kuperwasser C, Bierie B, Weinberg RA. Normal and neoplastic nonstem cells can spontaneously convert to a stemlike state. Proc Natl Acad Sci U S A 2011; 108(19): 7950-7955

31. Chaffer CL, Marjanovic ND, Lee T, Bell G, Kleer CG, Reinhardt F, D'Alessio AC, Young RA, Weinberg RA. Poised chromatin at the ZEB1 promoter enables breast cancer cell plasticity and enhances tumorigenicity. Cell 2013; 154(1): 61-74

32. Del Pozo Martin Y, Park D, Ramachandran A, Ombrato L, Calvo F, Chakravarty P, Spencer-Dene B, Derzsi S, Hill CS, Sahai E,
Malanchi I. Mesenchymal cancer cell-stroma crosstalk promotes niche activation, epithelial reversion, and metastatic colonization. Cell Rep 2015; 13(11): 2456-2469

33. Bierie B, Pierce SE, Kroeger C, Stover DG, Pattabiraman DR, Thiru P, Liu Donaher J, Reinhardt F, Chaffer CL, Keckesova Z, Weinberg RA. Integrin- $\beta 4$ identifies cancer stem cell-enriched populations of partially mesenchymal carcinoma cells. Proc Natl Acad Sci U S A 2017; 114(12): E2337-E2346

34. Mehlen P, Puisieux A. Metastasis: a question of life or death. Nat Rev Cancer 2006; 6(6): 449-458

35. Yang J, Mani SA, Donaher JL, Ramaswamy S, Itzykson RA, Come C, Savagner P, Gitelman I, Richardson A, Weinberg RA. Twist, a master regulator of morphogenesis, plays an essential role in tumor metastasis. Cell 2004; 117(7): 927-939

36. Krebs AM, Mitschke J, Lasierra Losada M, Schmalhofer O, Boerries M, Busch H, Boettcher M, Mougiakakos D, Reichardt W, Bronsert P, Brunton VG, Pilarsky C, Winkler TH, Brabletz S, Stemmler MP, Brabletz T. The EMT-activator Zeb1 is a key factor for cell plasticity and promotes metastasis in pancreatic cancer. Nat Cell Biol 2017; 19(5): 518-529

37. Friedl P, Locker J, Sahai E, Segall JE. Classifying collective cancer cell invasion. Nat Cell Biol 2012; 14(8): 777-783

38. Friedl P, Gilmour D. Collective cell migration in morphogenesis, regeneration and cancer. Nat Rev Mol Cell Biol 2009; 10(7): 445457

39. Cheung KJ, Padmanaban V, Silvestri V, Schipper K, Cohen JD, Fairchild AN, Gorin MA, Verdone JE, Pienta KJ, Bader JS, Ewald AJ. Polyclonal breast cancer metastases arise from collective dissemination of keratin 14-expressing tumor cell clusters. Proc Natl Acad Sci U S A 2016; 113(7): E854-E863

40. Aceto N, Bardia A, Miyamoto DT, Donaldson MC, Wittner BS, Spencer JA, Yu M, Pely A, Engstrom A, Zhu H, Brannigan BW, Kapur R, Stott SL, Shioda T, Ramaswamy S, Ting DT, Lin CP, Toner M, Haber DA, Maheswaran S. Circulating tumor cell clusters are oligoclonal precursors of breast cancer metastasis. Cell 2014; 158(5): 1110-1122

41. Revenu C, Gilmour D. EMT 2.0: shaping epithelia through collective migration. Curr Opin Genet Dev 2009; 19(4): 338-342

42. Westcott JM, Prechtl AM, Maine EA, Dang TT, Esparza MA, Sun H, Zhou Y, Xie Y, Pearson GW. An epigenetically distinct breast cancer cell subpopulation promotes collective invasion. J Clin Invest 2015; 125(5): 1927-1943

43. Puram SV, Tirosh I, Parikh AS, Patel AP, Yizhak K, Gillespie S, Rodman C, Luo CL, Mroz EA, Emerick KS, Deschler DG, Varvares MA, Mylvaganam R, Rozenblatt-Rosen O, Rocco JW, Faquin WC, Lin DT, Regev A, Bernstein BE. Single-cell transcriptomic analysis of primary and metastatic tumor ecosystems in head and neck cancer. Cell 2017; 171(7): 1611-1624. e24

44. Kourtidis A, Ngok SP, Pulimeno P, Feathers RW, Carpio LR, Baker TR, Carr JM, Yan IK, Borges S, Perez EA, Storz P, Copland JA, Patel T, Thompson EA, Citi S, Anastasiadis PZ. Distinct Ecadherin-based complexes regulate cell behaviour through miRNA processing or Src and p120 catenin activity. Nat Cell Biol 2015; 17 (9): 1145-1157

45. Yu M, Bardia A, Wittner BS, Stott SL, Smas ME, Ting DT, Isakoff SJ, Ciciliano JC, Wells MN, Shah AM, Concannon KF, Donaldson 
MC, Sequist LV, Brachtel E, Sgroi D, Baselga J, Ramaswamy S, Toner M, Haber DA, Maheswaran S. Circulating breast tumor cells exhibit dynamic changes in epithelial and mesenchymal composition. Science 2013; 339(6119): 580-584

46. Naumov GN, MacDonald IC, Weinmeister PM, Kerkvliet N, Nadkarni KV, Wilson SM, Morris VL, Groom AC, Chambers AF. Persistence of solitary mammary carcinoma cells in a secondary site: a possible contributor to dormancy. Cancer Res 2002; 62(7): 2162-2168

47. Heiss MM, Allgayer H, Gruetzner KU, Funke I, Babic R, Jauch KW, Schildberg FW. Individual development and uPA-receptor expression of disseminated tumour cells in bone marrow: a reference to early systemic disease in solid cancer. Nat Med 1995; 1(10): 1035-1039

48. Meng S, Tripathy D, Frenkel EP, Shete S, Naftalis EZ, Huth JF, Beitsch PD, Leitch M, Hoover S, Euhus D, Haley B, Morrison L, Fleming TP, Herlyn D, Terstappen LWMM, Fehm T, Tucker TF, Lane N, Wang J, Uhr JW. Circulating tumor cells in patients with breast cancer dormancy. Clin Cancer Res 2004; 10(24): 81528162

49. Aguirre-Ghiso JA. Models, mechanisms and clinical evidence for cancer dormancy. Nat Rev Cancer 2007; 7(11): 834-846

50. Braun S, Vogl FD, Naume B, Janni W, Osborne MP, Coombes RC, Schlimok G, Diel IJ, Gerber B, Gebauer G, Pierga JY, Marth C, Oruzio D, Wiedswang G, Solomayer EF, Kundt G, Strobl B, Fehm T, Wong GYC, Bliss J, Vincent-Salomon A, Pantel K. A pooled analysis of bone marrow micrometastasis in breast cancer. N Engl J Med 2005; 353(8): 793-802

51. Hüsemann Y, Geigl JB, Schubert F, Musiani P, Meyer M, Burghart E, Forni G, Eils R, Fehm T, Riethmüller G, Klein CA. Systemic spread is an early step in breast cancer. Cancer Cell 2008; 13(1): 58-68

52. Rhim AD, Mirek ET, Aiello NM, Maitra A, Bailey JM, McAllister F, Reichert M, Beatty GL, Rustgi AK, Vonderheide RH, Leach SD, Stanger BZ. EMT and dissemination precede pancreatic tumor formation. Cell 2012; 148(1-2): 349-361

53. Klein CA. Selection and adaptation during metastatic cancer progression. Nature 2013; 501(7467): 365-372

54. Takano S, Reichert M, Bakir B, Das KK, Nishida T, Miyazaki M, Heeg S, Collins MA, Marchand B, Hicks PD, Maitra A, Rustgi AK. Prrx1 isoform switching regulates pancreatic cancer invasion and metastatic colonization. Genes Dev 2016; 30(2): 233-247

55. Berx G, Cleton-Jansen AM, Strumane K, de Leeuw WJ, Nollet F, van Roy F, Cornelisse C. E-cadherin is inactivated in a majority of invasive human lobular breast cancers by truncation mutations throughout its extracellular domain. Oncogene 1996; 13(9): 19191925

56. Gerlinger M, Rowan AJ, Horswell S, Math M, Larkin J, Endesfelder D, Gronroos E, Martinez P, Matthews N, Stewart A, Tarpey P, Varela I, Phillimore B, Begum S, McDonald NQ, Butler A, Jones D, Raine K, Latimer C, Santos CR, Nohadani M, Eklund AC, Spencer-Dene B, Clark G, Pickering L, Stamp G, Gore M, Szallasi Z, Downward J, Futreal PA, Swanton C. Intratumor heterogeneity and branched evolution revealed by multiregion sequencing. N Engl J Med 2012; 366(10): 883-892

57. Shackleton M, Quintana E, Fearon ER, Morrison SJ. Heterogeneity in cancer: cancer stem cells versus clonal evolution. Cell
2009; 138(5): 822-829

58. Meacham CE, Morrison SJ. Tumour heterogeneity and cancer cell plasticity. Nature 2013; 501(7467): 328-337

59. Dagogo-Jack I, Shaw AT. Tumour heterogeneity and resistance to cancer therapies. Nat Rev Clin Oncol 2018; 15(2): 81-94

60. Burrell RA, McGranahan N, Bartek J, Swanton C. The causes and consequences of genetic heterogeneity in cancer evolution. Nature 2013; 501(7467): 338-345

61. Koren S, Reavie L, Couto JP, De Silva D, Stadler MB, Roloff T, Britschgi A, Eichlisberger T, Kohler H, Aina O, Cardiff RD, Bentires-Alj M. PIK3CA(H1047R) induces multipotency and multi-lineage mammary tumours. Nature 2015; 525(7567): 114118

62. Mu P, Zhang Z, Benelli M, Karthaus WR, Hoover E, Chen CC, Wongvipat J, Ku SY, Gao D, Cao Z, Shah N, Adams EJ, Abida W, Watson PA, Prandi D, Huang CH, de Stanchina E, Lowe SW, Ellis L, Beltran H, Rubin MA, Goodrich DW, Demichelis F, Sawyers CL. SOX2 promotes lineage plasticity and antiandrogen resistance in TP53- and RB1-deficient prostate cancer. Science 2017; 355 (6320): 84-88

63. Ku SY, Rosario S, Wang Y, Mu P, Seshadri M, Goodrich ZW, Goodrich MM, Labbé DP, Gomez EC, Wang J, Long HW, Xu B, Brown M, Loda M, Sawyers CL, Ellis L, Goodrich DW. Rb1 and Trp53 cooperate to suppress prostate cancer lineage plasticity, metastasis, and antiandrogen resistance. Science 2017; 355(6320): $78-83$

64. Pastushenko I, Brisebarre A, Sifrim A, Fioramonti M, Revenco T, Boumahdi S, Van Keymeulen A, Brown D, Moers V, Lemaire S, De Clercq S, Minguijón E, Balsat C, Sokolow Y, Dubois C, De Cock F, Scozzaro S, Sopena F, Lanas A, D’Haene N, Salmon I, Marine JC, Voet T, Sotiropoulou PA, Blanpain C. Identification of the tumour transition states occurring during EMT. Nature 2018; 556(7702): 463-468

65. Thiery JP, Acloque H, Huang RYJ, Nieto MA. Epithelialmesenchymal transitions in development and disease. Cell 2009; 139(5): 871-890

66. Dembinski JL, Krauss S. Characterization and functional analysis of a slow cycling stem cell-like subpopulation in pancreas adenocarcinoma. Clin Exp Metastasis 2009; 26(7): 611-623

67. Vega S, Morales AV, Ocaña OH, Valdés F, Fabregat I, Nieto MA. Snail blocks the cell cycle and confers resistance to cell death. Genes Dev 2004; 18(10): 1131-1143

68. Saxena M, Stephens MA, Pathak H, Rangarajan A. Transcription factors that mediate epithelial-mesenchymal transition lead to multidrug resistance by upregulating $\mathrm{ABC}$ transporters. Cell Death Dis 2011; 2(7): e179-e179

69. Gjerdrum C, Tiron C, Høiby T, Stefansson I, Haugen H, Sandal T, Collett K, Li S, McCormack E, Gjertsen BT, Micklem DR, Akslen LA, Glackin C, Lorens JB. Axl is an essential epithelial-tomesenchymal transition-induced regulator of breast cancer metastasis and patient survival. Proc Natl Acad Sci U S A 2010; 107(3): 1124-1129

70. Byers LA, Diao L, Wang J, Saintigny P, Girard L, Peyton M, Shen L, Fan Y, Giri U, Tumula PK, Nilsson MB, Gudikote J, Tran H, Cardnell RJG, Bearss DJ, Warner SL, Foulks JM, Kanner SB, Gandhi V, Krett N, Rosen ST, Kim ES, Herbst RS, Blumenschein GR, Lee JJ, Lippman SM, Ang KK, Mills GB, Hong WK, 
Weinstein JN, Wistuba II, Coombes KR, Minna JD, Heymach JV. An epithelial-mesenchymal transition gene signature predicts resistance to EGFR and PI3K inhibitors and identifies Axl as a therapeutic target for overcoming EGFR inhibitor resistance. Clin Cancer Res 2013; 19(1): 279-290

71. Hata AN, Niederst MJ, Archibald HL, Gomez-Caraballo M, Siddiqui FM, Mulvey HE, Maruvka YE, Ji F, Bhang HEC, Krishnamurthy Radhakrishna V, Siravegna G, Hu H, Raoof S, Lockerman E, Kalsy A, Lee D, Keating CL, Ruddy DA, Damon LJ, Crystal AS, Costa C, Piotrowska Z, Bardelli A, Iafrate AJ, Sadreyev RI, Stegmeier F, Getz G, Sequist LV, Faber AC, Engelman JA. Tumor cells can follow distinct evolutionary paths to become resistant to epidermal growth factor receptor inhibition. Nat Med 2016; 22(3): 262-269

72. Bhang HEC, Ruddy DA, Krishnamurthy Radhakrishna V, Caushi JX, Zhao R, Hims MM, Singh AP, Kao I, Rakiec D, Shaw P, Balak M, Raza A, Ackley E, Keen N, Schlabach MR, Palmer M, Leary RJ, Chiang DY, Sellers WR, Michor F, Cooke VG, Korn JM, Stegmeier F. Studying clonal dynamics in response to cancer therapy using high-complexity barcoding. Nat Med 2015; 21(5): 440-448

73. Terry S, Savagner P, Ortiz-Cuaran S, Mahjoubi L, Saintigny P, Thiery JP, Chouaib S. New insights into the role of EMT in tumor immune escape. Mol Oncol 2017; 11(7): 824-846

74. Hamilton DH, Huang B, Fernando RI, Tsang KY, Palena C. WEE1 inhibition alleviates resistance to immune attack of tumor cells undergoing epithelial-mesenchymal transition. Cancer Res 2014; 74(9): 2510-2519

75. Akalay I, Janji B, Hasmim M, Noman MZ, André F, De Cremoux P, Bertheau P, Badoual C, Vielh P, Larsen AK, Sabbah M, Tan TZ, Keira JH, Hung NTY, Thiery JP, Mami-Chouaib F, Chouaib S. Epithelial-to-mesenchymal transition and autophagy induction in breast carcinoma promote escape from T-cell-mediated lysis. Cancer Res 2013; 73(8): 2418-2427

76. Dongre A, Rashidian M, Reinhardt F, Bagnato A, Keckesova Z, Ploegh HL, Weinberg RA. Epithelial-to-mesenchymal transition contributes to immunosuppression in breast carcinomas. Cancer Res 2017; 77(15): 3982-3989

77. Chen L, Gibbons DL, Goswami S, Cortez MA, Ahn YH, Byers LA, Zhang X, Yi X, Dwyer D, Lin W, Diao L, Wang J, Roybal J, Patel M, Ungewiss C, Peng D, Antonia S, Mediavilla-Varela M, Robertson G, Suraokar M, Welsh JW, Erez B, Wistuba II, Chen L, Peng D, Wang S, Ullrich SE, Heymach JV, Kurie JM, Qin FXF. Metastasis is regulated via microRNA-200/ZEB1 axis control of tumour cell PD-L1 expression and intratumoral immunosuppression. Nat Commun 2014; 5(1): 5241

78. Noman MZ, Janji B, Abdou A, Hasmim M, Terry S, Tan TZ, Mami-Chouaib F, Thiery JP, Chouaib S. The immune checkpoint ligand PD-L1 is upregulated in EMT-activated human breast cancer cells by a mechanism involving ZEB-1 and miR-200. Oncoimmunology 2017; 6(1): e1263412

79. Kudo-Saito C, Shirako H, Takeuchi T, Kawakami Y. Cancer metastasis is accelerated through immunosuppression during Snail-induced EMT of cancer cells. Cancer Cell 2009; 15(3): 195-206

80. Peinado H, Olmeda D, Cano A. Snail, Zeb and bHLH factors in tumour progression: an alliance against the epithelial phenotype?
Nat Rev Cancer 2007; 7(6): 415-428

81. Lamouille S, Xu J, Derynck R. Molecular mechanisms of epithelial-mesenchymal transition. Nat Rev Mol Cell Biol 2014; 15(3): 178-196

82. Zheng X, Carstens JL, Kim J, Scheible M, Kaye J, Sugimoto H, $\mathrm{Wu}$ CC, LeBleu VS, Kalluri R. Epithelial-to-mesenchymal transition is dispensable for metastasis but induces chemoresistance in pancreatic cancer. Nature 2015; 527(7579): 525-530

83. Aiello NM, Brabletz T, Kang Y, Nieto MA, Weinberg RA, Stanger BZ. Upholding a role for EMT in pancreatic cancer metastasis. Nature 2017; 547(7661): E7-E8

84. Quail DF, Joyce JA. Microenvironmental regulation of tumor progression and metastasis. Nat Med 2013; 19(11): 1423-1437

85. Gregory PA, Bert AG, Paterson EL, Barry SC, Tsykin A, Farshid G, Vadas MA, Khew-Goodall Y, Goodall GJ. The miR-200 family and miR-205 regulate epithelial to mesenchymal transition by targeting ZEB1 and SIP1. Nat Cell Biol 2008; 10(5): 593-601

86. Park SM, Gaur AB, Lengyel E, Peter ME. The miR-200 family determines the epithelial phenotype of cancer cells by targeting the E-cadherin repressors ZEB1 and ZEB2. Genes Dev 2008; 22(7): 894-907

87. Korpal M, Lee ES, Hu G, Kang Y. The miR-200 family inhibits epithelial-mesenchymal transition and cancer cell migration by direct targeting of E-cadherin transcriptional repressors ZEB1 and ZEB2. J Biol Chem 2008; 283(22): 14910-14914

88. Siemens H, Jackstadt R, Hünten S, Kaller M, Menssen A, Götz U, Hermeking H. miR-34 and SNAIL form a double-negative feedback loop to regulate epithelial-mesenchymal transitions. Cell Cycle 2011; 10(24): 4256-4271

89. Chakrabarti R, Hwang J, Andres Blanco M, Wei Y, Lukačišin M, Romano RA, Smalley K, Liu S, Yang Q, Ibrahim T, Mercatali L, Amadori D, Haffty BG, Sinha S, Kang Y. Elf5 inhibits the epithelial-mesenchymal transition in mammary gland development and breast cancer metastasis by transcriptionally repressing Snail 2 . Nat Cell Biol 2012; 14(11): 1212-1222

90. Cieply B, Riley P 4th, Pifer PM, Widmeyer J, Addison JB, Ivanov AV, Denvir J, Frisch SM. Suppression of the epithelialmesenchymal transition by Grainyhead-like-2. Cancer Res 2012; 72(9): 2440-2453

91. Watanabe K, Villarreal-Ponce A, Sun P, Salmans ML, Fallahi M, Andersen B, Dai X. Mammary morphogenesis and regeneration require the inhibition of EMT at terminal end buds by Ovol2 transcriptional repressor. Dev Cell 2014; 29(1): 59-74

92. Chang CJ, Chao CH, Xia W, Yang JY, Xiong Y, Li CW, Yu WH, Rehman SK, Hsu JL, Lee HH, Liu M, Chen CT, Yu D, Hung MC. p53 regulates epithelial-mesenchymal transition and stem cell properties through modulating miRNAs. Nat Cell Biol 2011; 13 (3): 317-323

93. Shapiro IM, Cheng AW, Flytzanis NC, Balsamo M, Condeelis JS, Oktay MH, Burge CB, Gertler FB. An EMT-driven alternative splicing program occurs in human breast cancer and modulates cellular phenotype. PLoS Genet 2011; 7(8): e1002218-e1002221

94. Warzecha CC, Sato TK, Nabet B, Hogenesch JB, Carstens RP. ESRP1 and ESRP2 are epithelial cell-type-specific regulators of FGFR2 splicing. Mol Cell 2009; 33(5): 591-601

95. Conn SJ, Pillman KA, Toubia J, Conn VM, Salmanidis M, Phillips CA, Roslan S, Schreiber AW, Gregory PA, Goodall GJ. The RNA 
binding protein quaking regulates formation of circRNAs. Cell 2015; 160(6): 1125-1134

96. Braeutigam C, Rago L, Rolke A, Waldmeier L, Christofori G, Winter J. The RNA-binding protein Rbfox2: an essential regulator of EMT-driven alternative splicing and a mediator of cellular invasion. Oncogene 2014; 33(9): 1082-1092

97. Peinado H, Ballestar E, Esteller M, Cano A. Snail mediates Ecadherin repression by the recruitment of the $\operatorname{Sin} 3 \mathrm{~A} /$ histone deacetylase 1 (HDAC1)/HDAC2 complex. Mol Cell Biol 2004; 24(1): 306-319

98. Lin Y, Wu Y, Li J, Dong C, Ye X, Chi YI, Evers BM, Zhou BP. The SNAG domain of Snaill functions as a molecular hook for recruiting lysine-specific demethylase 1. EMBO J 2010; 29(11): 1803-1816

99. Herranz N, Pasini D, Díaz VM, Francí C, Gutierrez A, Dave N, Escrivà M, Hernandez-Muñoz I, Di Croce L, Helin K, García de Herreros A, Peiró S. Polycomb complex 2 is required for Ecadherin repression by the Snaill transcription factor. Mol Cell Biol 2008; 28(15): 4772-4781

100. Zhou BP, Deng J, Xia W, Xu J, Li YM, Gunduz M, Hung MC. Dual regulation of Snail by GSK-3 $\beta$-mediated phosphorylation in control of epithelial-mesenchymal transition. Nat Cell Biol 2004; 6 (10): 931-940

101. Hong J, Zhou J, Fu J, He T, Qin J, Wang L, Liao L, Xu J. Phosphorylation of serine 68 of Twist1 by MAPKs stabilizes Twist1 protein and promotes breast cancer cell invasiveness. Cancer Res 2011; 71(11): 3980-3990

102. Xu J, Lamouille S, Derynck R. TGF- $\beta$-induced epithelial to mesenchymal transition. Cell Res 2009; 19(2): 156-172

103. Brown KA, Aakre ME, Gorska AE, Price JO, Eltom SE, Pietenpol JA, Moses HL. Induction by transforming growth factor- $\beta 1$ of epithelial to mesenchymal transition is a rare event in vitro. Breast Cancer Res 2004; 6(3): R215-R231

104. Lu H, Clauser KR, Tam WL, Fröse J, Ye X, Eaton EN, Reinhardt F, Donnenberg VS, Bhargava R, Carr SA, Weinberg RA. A breast cancer stem cell niche supported by juxtacrine signalling from monocytes and macrophages. Nat Cell Biol 2014; 16(11): 11051117

105. Li HJ, Reinhardt F, Herschman HR, Weinberg RA. Cancerstimulated mesenchymal stem cells create a carcinoma stem cell niche via prostaglandin E2 signaling. Cancer Discov 2012; 2(9): 840-855

106. Byers L, Gerber D, Peguero J, Micklem D, Yule M, Lorens JB. A phase I/II and pharmacokinetic study of BGB324, a selective AXL inhibitor as monotherapy and in combination with erlotinib in patients with advanced non-small cell lung cancer (NSCLC). Eur J Cancer 2016; 69: S18-S19

107. Sheridan C. First Axl inhibitor enters clinical trials. Nat Biotechnol 2013; 31(9): 775-776

108. Hangauer MJ, Viswanathan VS, Ryan MJ, Bole D, Eaton JK, Matov A, Galeas J, Dhruv HD, Berens ME, Schreiber SL, McCormick F, McManus MT. Drug-tolerant persister cancer cells are vulnerable to GPX4 inhibition. Nature 2017; 551(7679): 247250

109. Viswanathan VS, Ryan MJ, Dhruv HD, Gill S, Eichhoff OM, Seashore-Ludlow B, Kaffenberger SD, Eaton JK, Shimada K, Aguirre AJ, Viswanathan SR, Chattopadhyay S, Tamayo P, Yang WS, Rees MG, Chen S, Boskovic ZV, Javaid S, Huang C, Wu X, Tseng YY, Roider EM, Gao D, Cleary JM, Wolpin BM, Mesirov JP, Haber DA, Engelman JA, Boehm JS, Kotz JD, Hon CS, Chen Y, Hahn WC, Levesque MP, Doench JG, Berens ME, Shamji AF, Clemons PA, Stockwell BR, Schreiber SL. Dependency of a therapy-resistant state of cancer cells on a lipid peroxidase pathway. Nature 2017; 547(7664): 453-457

110. Pattabiraman DR, Bierie B, Kober KI, Thiru P, Krall JA, Zill C, Reinhardt F, Tam WL, Weinberg RA. Activation of PKA leads to mesenchymal-to-epithelial transition and loss of tumor-initiating ability. Science 2016; 351(6277): aad3680

111. Herbertz S, Sawyer JS, Stauber AJ, Gueorguieva I, Driscoll KE, Estrem ST, Cleverly AL, Desaiah D, Guba SC, Benhadji KA, Slapak CA, Lahn MM. Clinical development of galunisertib (LY2157299 monohydrate), a small molecule inhibitor of transforming growth factor- $\beta$ signaling pathway. Drug Des Devel Ther 2015; 9: 4479-4499

112. Liu X, Sun H, Qi J, Wang L, He S, Liu J, Feng C, Chen C, Li W, Guo Y, Qin D, Pan G, Chen J, Pei D, Zheng H. Sequential introduction of reprogramming factors reveals a time-sensitive requirement for individual factors and a sequential EMT-MET mechanism for optimal reprogramming. Nat Cell Biol 2013; 15(7): 829-838 